\title{
Ex Situ Scanning Electrochemical Microscopy (SECM) Investigation of Bismuth- and Bismuth/Lead Alloy Film-Modified Gold Electrodes in Alkaline Medium
}

\author{
Maiara Oliveira Salles, ${ }^{\mathrm{a}}$ Dario Battistel, ${ }^{\mathrm{b}}$ Alex Silva Lima, ${ }^{\mathrm{a}}$ Mauro Bertotti, ${ }^{\mathrm{a}}$ Salvatore Daniele ${ }^{\mathrm{*}}$ \\ a Institute of Chemistry, University of São Paulo, Av. Professor Lineu Prestes, 748, 05513-970 São Paulo, Brazil \\ b Department of Physical Chemistry, University of Venice, Calle Larga, S. Marta, 2137, 30123 Venice, Italy \\ tel. $+390412348630 ;$ fax +390412348594 \\ *e-mail: sig@unive.it
}

Received: August 23, 2010

Accepted: October 18, 2010

\begin{abstract}
Scanning electrochemical microscopy (SECM) in feedback mode was employed to characterise the reactivity and microscopic peculiarities of bismuth and bismuth/lead alloys plated onto gold disk substrates in $0.1 \mathrm{~mol} \mathrm{~L}^{-1} \mathrm{NaOH}$ solutions. Methyl viologen was used as redox mediator, while a platinum microelectrode was employed as the SECM tip. The metal films were electrodeposited ex situ from $\mathrm{NaOH}$ solutions containing either bismuth ions only or both bismuth and lead ions. Approach curves and SECM images indicated that the metal films were conductive and locally reactive with oxygen to provide $\mathrm{Bi}^{3+}$ and $\mathrm{Pb}^{2+}$ ions. The occurrence of the latter chemical reactions was verified by local anodic stripping voltammetry (ASV) at the substrate solution interface by using a mercury-coated platinum SECM tip. The latter types of measurements allowed also verifying that lead was not uniformly distributed onto the bismuth film electrode substrate. These findings were confirmed by scanning electron microscopy images. The surface heterogeneity produced during the metal deposition process, however, did not affect the analytical performance of the bismuth coated gold electrode in anodic stripping voltammetry for the determination of lead in alkaline media, even in aerated aqueous solutions. Under the latter conditions, stripping peak currents proportional to lead concentration with a satisfactory reproducibility (within $5 \% R S D$ ) were obtained.
\end{abstract}

Keywords: Bismuth film, Gold electrodes, Anodic stripping voltammetry, SECM, Alkaline medium

DOI: 10.1002/elan.201000528

\section{Introduction}

Since their introduction in 2000 by Wang et. al. [1], bismuth film electrodes (BiFEs) have received much attention, as alternative to mercury film electrodes, with regards to their use in anodic stripping voltammetry (ASV). Corresponding research efforts have produced a number of possible analytical applications, which are documented in several papers and reviews [1-10]. It is now generally established that the electroanalytical performance of BiFEs compare well with those of the analogous mercury film electrodes. In addition, BiFEs overcome environmental concerns related to mercury toxicity [1].

BiFEs can be prepared by either ex situ or in situ procedures by electrodeposition of metallic bismuth from solutions containing bismuth ions on substrate materials such as various types of carbon materials [1-3, 8,9,11-15], copper [16,17], platinum [3] and gold [3,11,18]. Carbon substrates have been the most common choice in ASV analysis, because of the wide cathodic window achievable, which is due to the high hydrogen overvoltage. Although much less employed, gold substrates have also displayed good performance for BiFEs preparation with the in situ procedure, especially for the detection of metal ions, such as $\mathrm{Cd}^{2+}, \mathrm{Pb}^{2+}, \mathrm{Tl}^{+}$, and $\mathrm{In}^{3+}$, which are deposited-stripped at not too negative potentials. It must be considered that the use of gold as substrate for bismuth film deposition poses questions about interactions between bismuth and gold, which provides intermetallic species, reflecting on a number of bismuth stripping peaks $[11,18]$.

Another usual preference in the proposed method employing in situ formed BiFEs is the use of acid media (i.e., acetate buffer has represented the dominating supporting medium) [1-3,11-14,17]. However, because of the chemical nature of $\mathrm{Bi}^{3+}$ ions, BiFEs can also be operated in highly alkaline media, as has been proven in a few papers for the detection of $\mathrm{Pb}, \mathrm{Cd}$, and $\mathrm{Tl}[12,19]$. Bismuth deposition from highly alkaline media is possible, because $\mathrm{Bi}^{3+}$ forms soluble complexes with hydroxide ions of the type $\left[\mathrm{Bi}(\mathrm{OH})_{n}\right]^{(3-n)},(n=1-4) \quad[12,19,20]$, which are readily reducible at the electrode surface:

$$
\left[\mathrm{Bi}(\mathrm{OH})_{n}\right]^{(3-n)}+3 \mathrm{e}^{-} \rightarrow \mathrm{Bi}^{0}+n \mathrm{OH}^{-} \quad(n=1-4)
$$

The use of alkaline media along with BiFEs in ASV has provided some advantages in the ASV responses with 
respect to the acidic media. In particular, improvements in the separation between $\mathrm{Cd}$ and $\mathrm{Tl}$ stripping peaks and sharper and more intense stripping peaks for $\mathrm{Pb}$ have been observed in $\mathrm{NaOH}$ solutions with respect to acetate buffer media $[12,19]$.

The performance of BiFEs in stripping analysis and peculiarities of film formation have recently been evaluated also by coupling voltammetric measurements with microscopic surface analysis of the deposited films. In particular, the effect of complexing agents [13,17,21] and the formation of bismuth/metal alloys [14] on structure and topography of the films have been evaluated by using scanning electron microscopy (SEM) and atomic force microscopy (AFM). In addition, reactivity and chemical stability of the BiFEs deposited on a glassy carbon substrate by an ex situ operating procedure has also been studied by scanning electrochemical microscopy (SECM) [13]. SECM [22,23], in fact, is a technique widely exploited to obtain valuable information concerning conductivity and spatial localization of chemical events that occur at the solid/solution interface of a variety of metals and thin solid films [13,22-29]. SECM operating in feedback mode forms the overwhelming majority of applications [22]. For these measurements the bulk solution contains the oxidised or reduced form of a reversible (or quasi-reversible) redox couple as mediator, and the amperometric response at the microelectrode tip is recorded as a function of the tip/substrate distance (so called approach curves) [22]. Theoretical approach curves have been derived for a variety of tip geometries and for a large number of chemical and electrochemical phenomena occurring at the substrate surface [29-37]. The comparison between experimental and theoretical approach curves allows obtaining relevant information on the investigated surfaces [22].

In this paper, SECM is used to characterise for the first time stability and chemical peculiarities of the bismuth film and of the co-deposited bismuth/lead alloys formed on a gold substrate in highly alkaline media under typical ASV operating conditions. Lead is considered as the target analyte because of its importance in environmental and health issues. Moreover, lead ions in very basic media are known to form the soluble complex $\left[\mathrm{Pb}(\mathrm{OH})_{4}\right]^{2-}$, which is also readily reducible at the electrode surface $[15,38]$. Because gold, contrary to carbon material substrates, can provide strong interactions with both bismuth and lead, surface heterogeneity may arise during plating, depending on whether only bismuth or bismuth and lead simultaneously are deposited under typical ASV operating conditions.

The SECM characterisation of the various substrates is performed ex situ, in a solution different from that employed for metals plating. In particular, most SECM experiments are performed in an aerated $0.1 \mathrm{molL}^{-1} \mathrm{KCl}$ solution containing methyl viologen (MV) as redox mediator. SECM results are also discussed on the light of SEM images acquired on the gold substrate after its modification with $\mathrm{Bi}$ and $\mathrm{Bi} / \mathrm{Pb}$ under similar experimental conditions.

\section{Experimental}

\subsection{Reagents and Solutions}

All chemicals employed were of analytical-reagent grade and used as received. $\mathrm{C}_{12} \mathrm{H}_{14} \mathrm{Cl}_{2} \mathrm{~N}_{2}$ (MV), $\mathrm{NaOH}$, $\mathrm{Bi}\left(\mathrm{NO}_{3}\right)_{3}\left(1000 \mathrm{ppm}\right.$ in $\left.5 \mathrm{wt} \% \mathrm{HNO}_{3}\right)$ and $\mathrm{KCl}$ were obtained from Aldrich; $\mathrm{Pb}\left(\mathrm{NO}_{3}\right)_{2}$ was obtained from Merck. $\mathrm{CH}_{3} \mathrm{COOH}, \mathrm{CH}_{3} \mathrm{COONa}, \mathrm{Hg}_{2}\left(\mathrm{NO}_{3}\right)_{2}$ and $\mathrm{KNO}_{3}$ were purchased from Fluka. All solutions were prepared by using water purified via a Milli-Q system (Millipore, Bedford, MA). Measurements, which required no oxygen, were carried out in solutions that had been purged with pure nitrogen $(99.99 \%$ ) (Purchased from SIAD, Bergamo, Italy).

\subsection{Apparatus}

Voltammetric measurements were performed in a threeelectrode electrochemical cell. A commercially available gold disk electrode $2 \mathrm{~mm}$ in diameter was employed as working/substrate electrode for deposition of bismuth and bismuth/lead alloy. Unless otherwise stated, a platinum microdisk of $25 \mu \mathrm{m}$ in diameter was employed as SECM tip-electrode. It was prepared by sealing a platinum wire of $25 \mu \mathrm{m}$ in diameter into a glass capillary, which was afterward tapered to a conical shape, such that the overall tip to electrode radius ratio ( $\mathrm{RG}$ ) was equal to 10 . For ASV local measurements at the substrate/solution interface, a hemispherical mercury microelectrode was employed. It was fabricated by cathodic deposition of liquid mercury onto a $25 \mu \mathrm{m}$ diameter platinum disk as reported in detail elsewhere [39-41]. The deposition was performed under potentiostatic conditions at $-0.1 \mathrm{~V}$ against an $\mathrm{Ag} / \mathrm{AgCl}$ reference electrode in a plating solution consisting of $5 \mathrm{mmol} \mathrm{L}^{-1} \mathrm{Hg}_{2}\left(\mathrm{NO}_{3}\right)_{2}$ in $1 \mathrm{~mol} \mathrm{~L}^{-1} \mathrm{KNO}_{3}$ acidified with nitric acid to $\mathrm{pH}<1$. The mercury microelectrode was characterised for voltammetric and SECM measurements as reported in refs [36,37].

The surface of all solid electrodes was polished with alumina powder $(1,0.3$ and $0.05 \mu \mathrm{m})$ on a polishing pad. $\mathrm{An} \mathrm{Ag} / \mathrm{AgCl}$ (sat. $\mathrm{KCl}$ ) was used as a reference electrode and a platinum wire as the counter electrode.

Voltammetric measurements were carried out with a CH760B potentiostat ( $\mathrm{CH}$ instruments), while SECM experiments were performed with a CHI920B workstation ( $\mathrm{CH}$ instruments). The electrodeposition of the metal films for SEM analysis was carried out with an Autolab PGSTAT 30 (Eco Chemie). SEM experiments were carried out in a SEM, JSM-7401F (JEOL).

\subsection{Preparation of Metal-Coated Gold Substrates}

Bismuth and bismuth/lead films deposited on gold were formed by plating the metal or alloy onto the gold disk 
substrates at $-1.0 \mathrm{~V}$ vs. $\mathrm{Ag} / \mathrm{AgCl}$ for $500 \mathrm{~s}$ from aqueous solutions containing, unless otherwise stated, $0.1 \mathrm{~mol} \mathrm{~L}^{-1}$ $\mathrm{NaOH}, 10 \mu \mathrm{mol} \mathrm{L}^{-1}$ bismuth(III) and $5 \mu \mathrm{molL}^{-1}$ lead(II), while the solutions were stirred. The metal and metal alloys modified gold electrodes once prepared were rinsed with Milli-Q water and transferred in the cell of the SECM apparatus. Then, the SECM measurements were started, typically, after about $5 \mathrm{~min}$ of immersion of the samples in the aerated aqueous solutions (see below).

\subsection{SECM Experiments}

Unless otherwise stated SECM experiments were performed in an electrochemical cell containing an aerated $0.1 \mathrm{molL}^{-1} \mathrm{KCl}$ aqueous solution, as base electrolyte and $20 \mathrm{mmol} \mathrm{L}^{-1}$ methyl viologen as redox mediator. All approach curves and SECM images were recorded with the Pt microdisk biased at $-0.80 \mathrm{~V}$, corresponding to the diffusion limiting current for the reduction: $\mathrm{MV}^{2+}+\mathrm{e}^{-} \rightarrow$ $\mathrm{MV}^{\cdot+}$. As is typical for SECM measurements [22], current $(I)$ data displayed either in the approach curves or SECM images were normalised for the diffusion limiting current $\left(I_{\text {bulk }}\right)$ determined experimentally with the platinum microtip located in the bulk solution in the presence of the redox mediator. Moreover, in the approach curves the tip to substrate distance $(d)$ was normalised by the radius of the platinum microdisk electrode $(a)$. Slow approach curves $\left(0.05 \mu \mathrm{m} \mathrm{s}^{-1}\right)$ were used for determining the zero distance taken when the glass insulator surrounding the microdisk contacted the substrate. The metal or alloy modified gold electrodes during SECM measurements were in any case unbiased.

\subsection{SEM Experiments}

SEM measurements were performed on metal films deposited onto a gold wire $100 \mu \mathrm{m}$ diameter, using the same metal deposition conditions as described in Section 2.3. All the metal fibres were left in an argon atmosphere until the beginning of the SEM experiments.

\section{Results and Discussion}

\subsection{General SECM Measurements}

As mentioned above, the analysis of the approach curves can provide useful information about the nature and reactivity of the investigated substrate. Thus, in order to characterise conductivity and reactivity of the investigated surfaces, families of approach curves were recorded above the investigated substrates, using $\mathrm{MV}^{2+}$ as redox mediator. Since SECM measurements were performed in aerated aqueous solutions, preliminary, the most suitable concentration of $\mathrm{MV}^{2+}$ to avoid interference from oxygen was investigated. This check was necessary as the reduction process of $\mathrm{MV}^{2+}$ occurs at potentials more negative than that of oxygen (see Figure 1 Inset). For this purpose a series of approach curves were recorded above a

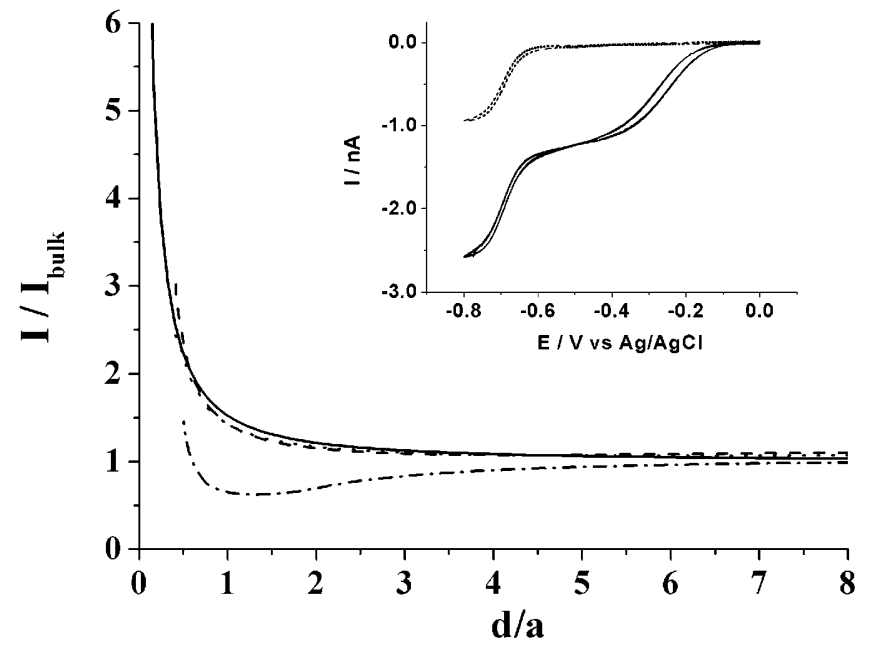

Fig. 1. Approach curves obtained with a platinum SECM tip above a gold electrode as the substrate and $\mathrm{MV}^{2+}$ as redox mediator. $\mathrm{MV}^{2+} 20 \mathrm{mmolL}^{-1}(---)$ and $1 \mathrm{mmolL}^{-1}(---)$; theoretical approach curve (-). $E_{\text {tip }}=-0.8 \mathrm{~V}$. Inset: Cyclic voltammograms recorded at a platinum microelectrode $(r=5 \mu \mathrm{m})$ in a solution

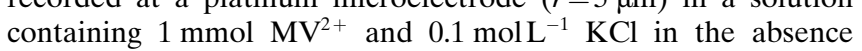
(.....) and presence (-) of oxygen. Scan rate: $50 \mathrm{mV} \mathrm{s}^{-1}$.

smooth and freshly polished gold or platinum substrate. As is evident in the main part of Figure 1 (which refers to the case of a gold substrate), a positive feedback approach curve (dashed line), which fit the diffusion controlled response (full line) for a conducting substrate, was observed provided that $\mathrm{MV}^{2+}$ concentration was higher than $10 \mathrm{mmolL}^{-1}$. At lower $\mathrm{MV}^{2+}$ concentrations oxygen interferences arose and a mixed negative/positive feedback response (dotted-dashed line) were obtained. Similar approach curves were obtained with the platinum substrate, thus indicating that the above behaviour was not due to the nature of the surface investigated. The mixed negative/positive approach curves obtained at low $\mathrm{MV}^{2+}$ concentrations were explained as due to the fact that oxygen reduction provides an irreversible four-electron process to water at the platinum SECM tip [42]. Consequently, at $-0.80 \mathrm{~V}$ the irreversible reduction of oxygen to water prevails, leading to an overall negative feedback approach curve for wide tip-substrate distances. The expected positive feedback response due to recycling of $\mathrm{MV}^{2+}$ prevails only at low tip/substrate distances $(d / a<$ 1 ), where diffusion of oxygen towards the platinum microdisk surface is hindered and therefore its contribution to the feedback response is negligibly low. Thus, to make the effect of oxygen negligible, further SECM experiments were performed with $20 \mathrm{mmol} \mathrm{L}^{-1} \mathrm{MV}^{2+}$.

\subsection{SECM Analysis of Bare Gold and Metal-Coated Gold Surfaces}

The surface status, in terms of conductivity and reactivity, of either the bare gold electrode or the metal-coated gold disk was investigated by SECM operating in feedback mode. Typical normalised approach curves recorded at 


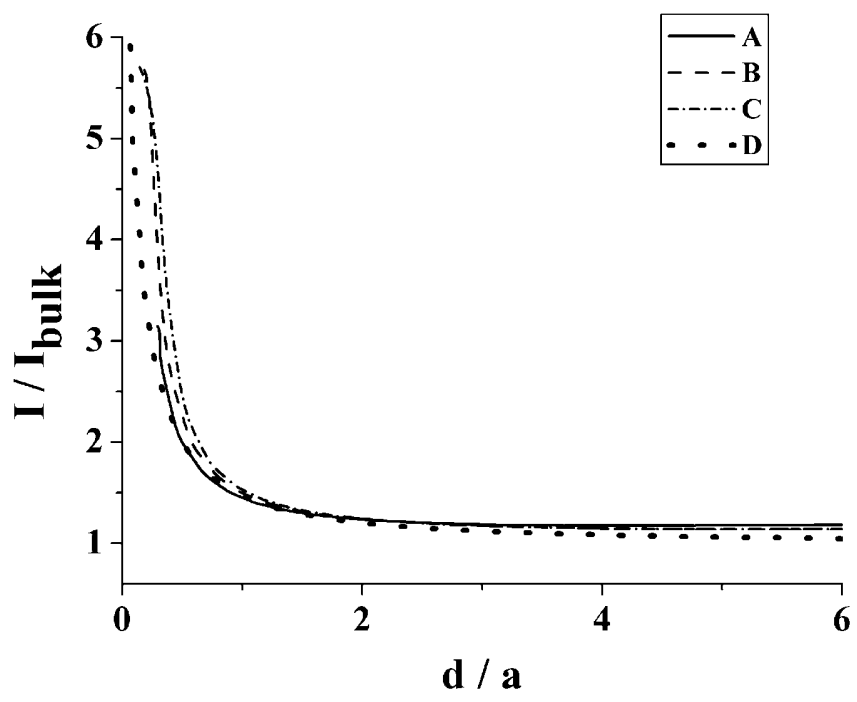

Fig. 2. Approach curves recorded at different substrates with $20 \mathrm{mmolL}^{-1} \mathrm{MV}^{2+}$ as redox mediator. Bare gold electrode (A); BiFE prepared without (B) and with lead (C); theoretical curve (D). $E_{\text {tip }}=-0.8 \mathrm{~V}$.

the uncoated gold substrate and at the bismuth and bismuth/lead coated gold electrodes are shown in Figure 2. As is evident, in all cases positive feedback was observed, as expected for large conductive substrates [22]. However, the current enhancements at close tip/substrate distances depended to a different extent on the nature of the surface investigated. In particular, the currents were larger at the metal-coated gold substrates. For a given substrate, changing the tip position above the substrate also led to a variation of the normalised current values (within $20 \%, R S D$, from at least 20 measurements). This was explained as due, conceivably, to surface roughness of the substrate electrode and/or lack of tip alignment. It must be noticed that the current enhancements observed while changing the nature of the substrate was always larger than that due to surface roughness.

As mentioned above, the approach curves recorded at the uncoated gold electrodes provided the lowest current enhancements. They, however, fit the theoretical diffusion controlled positive feedback approach curve [31] (Figure 2 dotted line), indicating that gold surface maintained its good conductivity, though it had been immersed in the alkaline medium for a rather long time. The origin of the extra currents recorded at the SECM tip while approaching the metal-coated gold substrates was explained as follows.

It is known that oxygen present in water can act as a natural oxidant of deposited metals [43]. This phenomenon was exploited in early applications of potentiometric stripping analysis (PSA) for the determination of a variety of metal ions or traces of dissolved oxygen [44]. On this ground, it is reasonable admitting that the metalcoated substrates being unbiased, once transferred in the SECM cell, can locally originate relatively high concentrations of their ions, which eventually can diffuse to- wards the bulk solution. The use of $\mathrm{MV}^{+}$as redox mediator implies that the tip is biased at a potential value where both $\mathrm{Pb}^{2+}$ and $\mathrm{Bi}^{3+}$ can be reduced, as can be inferred from the redox potentials of the species involved in the measurements (see Table 1). Thus, as the SECM tip is approaching the substrate, along with the current contribution due to the recycling of the redox mediator due to lateral charge transfer [22], extra current can arise due to the reduction of $\mathrm{Bi}^{3+}$ and $\mathrm{Pb}^{2+}$ ions generated at the substrate. Furthermore, the metal oxidation process due to oxygen may afford $\mathrm{H}_{2} \mathrm{O}_{2}[42,43]$, which is also reducible at the platinum tip. It must be noted that the amount of $\mathrm{Bi}^{3+}$ and $\mathrm{Pb}^{2+}$ ions generated locally, and consequently the extra current recorded, depended to some extent also on the lapse of time, since the sample had been immersed in the SECM cell.

In order to verify that $\mathrm{Bi}^{3+}$ and $\mathrm{Pb}^{2+}$ were actually formed at the metal-coated gold/water interface, local metal ion analyses were performed with a mercury microelectrode by combining ASV with SECM. In fact, the latter approach proved useful for sensitive and high-spatial resolution analysis of metal ions at a variety of solid/ solution interfaces [36,45-51]. For these measurements the metal-coated gold substrates, once prepared in the alkaline solution as described above, were transferred in the SECM cell containing $0.1 \mathrm{molL}^{-1}$ acetate buffer ( $\mathrm{pH}$ 4.5). Moreover, a hemispherical mercury microelectrode was employed as a SECM tip. It was positioned at $5 \mu \mathrm{m}$ above the substrate using approach curves recorded with the tip biased at $-0.5 \mathrm{~V}$, where oxygen reduction occurs [36]. The local ASV measurements were performed using a deposition potential of $-1.0 \mathrm{~V}$ and a deposition time of $300 \mathrm{~s}$. In all cases the substrates were unbiased. Figure 3 a shows a typical stripping voltammogram obtained under the above experimental conditions, using linear sweep voltammetry at $50 \mathrm{mV} \mathrm{s}^{-1}$ during the anodic scan. As is evident, two main peaks at about $-0.4 \mathrm{~V}$ and $0 \mathrm{~V}$ are recorded. They were attributed to lead and bismuth, respectively, by comparing ASV measurements (Figure 3b) performed with the same mercury microelectrode in an aerated acetate buffer aqueous solutions spiked with known amounts of $\mathrm{Bi}^{3+}$ and $\mathrm{Pb}^{2+}$ ions. From Figure $3 \mathrm{a}$ it is also evident that the stripping peaks emerge from a negative plateau current, which is due to the diffusion controlled oxygen reduction process [36]. A further consideration that can be drawn from Figure 3 is that the ASV peak potentials are such that at $-0.8 \mathrm{~V}$, at which the SECM tip was biased during the acquisition of the approach curves in Figure 2, both $\mathrm{Bi}^{3+}$ and $\mathrm{Pb}^{2+}$ ions can be reduced. Thus, although the redox potentials shown in Table 1 do not correspond to those of the experimental conditions employed, their sequence still applies.

A series of ASV-SECM measurements was also performed in different locations above the metal-coated gold substrate, and Figure 4 shows typical stripping voltammograms thus recorded. It is evident that, while the height of the $\mathrm{Bi}$ peak is almost constant regardless of the tip position, the $\mathrm{Pb}$ peak height changes from one position to 


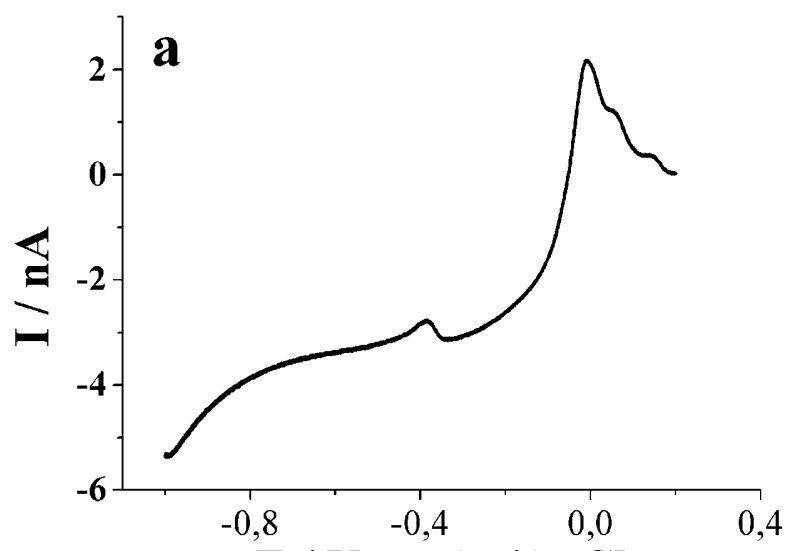

E / V vs. Ag/AgCl

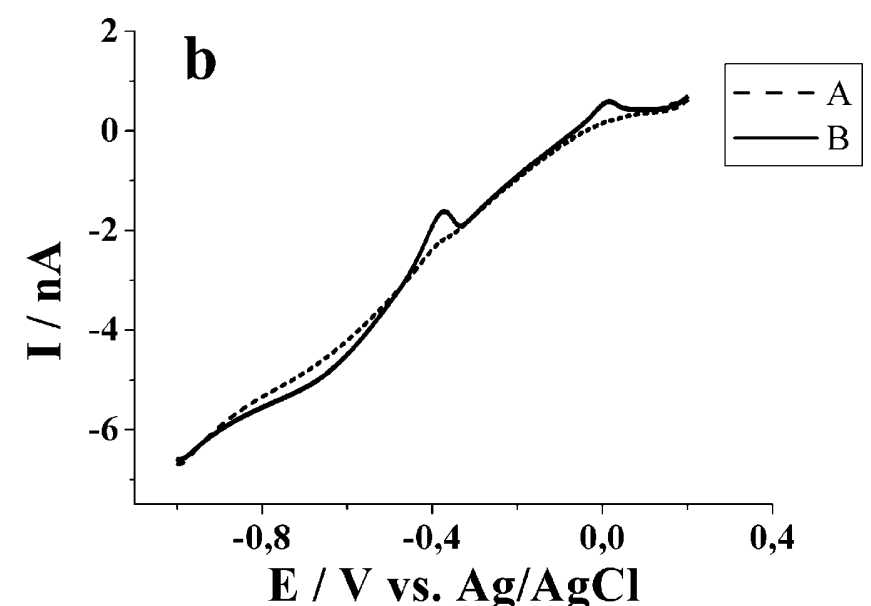

Fig. 3. ASVs obtained with a mercury microelectrode in $0.1 \mathrm{~mol} \mathrm{~L}^{-1}$ acetate buffer solution $\mathrm{pH}=4.5$. (a) Microelectrode positioned at $5 \mu \mathrm{m}$ above the gold substrate modified with an alloy of bismuth and lead. (b) Microelectrode positioned in the bulk of a $0.1 \mathrm{molL}^{-1}$ acetate buffer solution $\mathrm{pH} 4.5$ (A), and after the solution was spiked with $0.1 \mu \mathrm{molL} \mathrm{L}^{-1} \mathrm{~Pb}^{2+}$ and $0.5 \mu \mathrm{molL} \mathrm{L}^{-1} \mathrm{Bi}^{3+}$ (B). Deposition potential $=-1.0 \mathrm{~V}$ and deposition time $=300 \mathrm{~s}$. Scan rate $50 \mathrm{mV}$ $\mathrm{s}^{-1}$

the other. This may be due to a nonhomogeneous distribution of lead deposit across the gold electrode surface upon metal plating in the $\mathrm{NaOH}$ medium. The latter aspect is discussed in the sections below.

\subsection{SECM Image}

Figure 5 shows typical SECM images recorded at the gold substrate either before or after its modification with a $\mathrm{Bi} /$ $\mathrm{Pb}$ film, using $\mathrm{MV}^{2+}$ as redox mediator. It is evident that in all cases positive feedback responses throughout the surfaces are recorded. Moreover, normalised current values are higher after modification of the gold electrode with the $\mathrm{Bi} / \mathrm{Pb}$ film, which agrees with the shape of the approach curves reported above. Some inhomogeneities of the metal-coated surfaces are also well evident in comparison with a relatively more uniform image of the uncoated gold surface. This circumstance was further con-

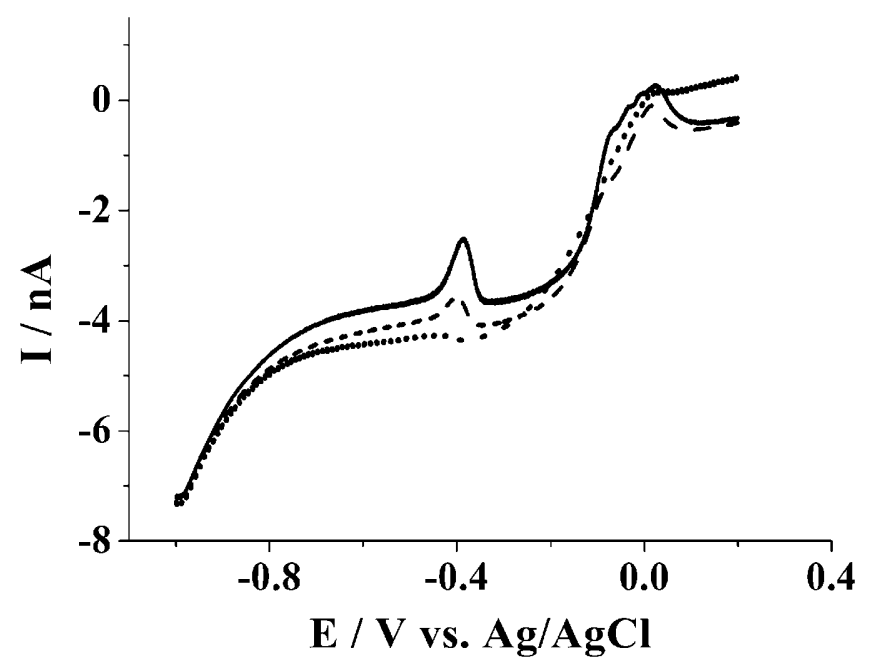

Fig. 4. Local ASVs obtained with a mercury microelectrode at different locations above the gold substrate modified with an alloy of bismuth and lead. Tip-substrate distance $5 \mu \mathrm{m}$. Deposition potential $=-1.0 \mathrm{~V}$ and deposition time $=300 \mathrm{~s}$. Scan rate $50 \mathrm{mV} \mathrm{s}^{-1}$

Table 1. Redox potentials of the species involved in the SECM experiments.

\begin{tabular}{lll}
\hline Redox couple & $E^{\circ}(\mathrm{V}$ vs. NHE) & References \\
\hline $\mathrm{MV}^{2+/ \cdot+}$ & -0.45 & {$[23]$} \\
$\mathrm{PbCl}_{2} / \mathrm{Pb}^{0}+2 \mathrm{Cl}^{-}$ & -0.2675 & {$[56]$} \\
$\mathrm{Pb}^{2+/ 0}$ & -0.1262 & {$[56]$} \\
$\mathrm{BiCl}_{4}^{-} / \mathrm{Bi}^{0}+4 \mathrm{Cl}^{-}$ & 0.160 & {$[56]$} \\
$\mathrm{Bi}^{3+/ 0}$ & 0.308 & {$[56]$} \\
\hline
\end{tabular}

firmed by recording SECM images at the gold electrodes after the metal deposits were stripped off (Figure 5C). As is evident, again, lower normalised currents apply at the gold substrate after metal stripping. The inhomogeneity was attributed to the nonuniform distribution of lead across the surface.

To further assess the degree of surface heterogeneity, SECM images obtained under the above different conditions were treated statistically. The root mean square current fluctuation $\left(R_{\mathrm{q}}\right)$ obtained within the area analysed of the various substrates was calculated by the following expression [13]:

$$
R_{\mathrm{q}}=\left[\sum\left(Z_{i}-Z_{\mathrm{ave}}\right)^{2} / N\right]^{1 / 2}
$$

where $Z_{\text {ave }}$ is the average of $Z$ values within the given area, $Z_{i}$ is the normalized current $Z$ value, and $N$ is the number of points within the area. Higher average normalised currents and higher normalised current fluctuations are indicative of a less uniform surface. The results obtained for an uncoated and metal-coated gold samples are listed in Table 2. These data clearly confirm that a more uniform surface applies for the bare gold electrode with respect to the metal-coated gold substrates. 


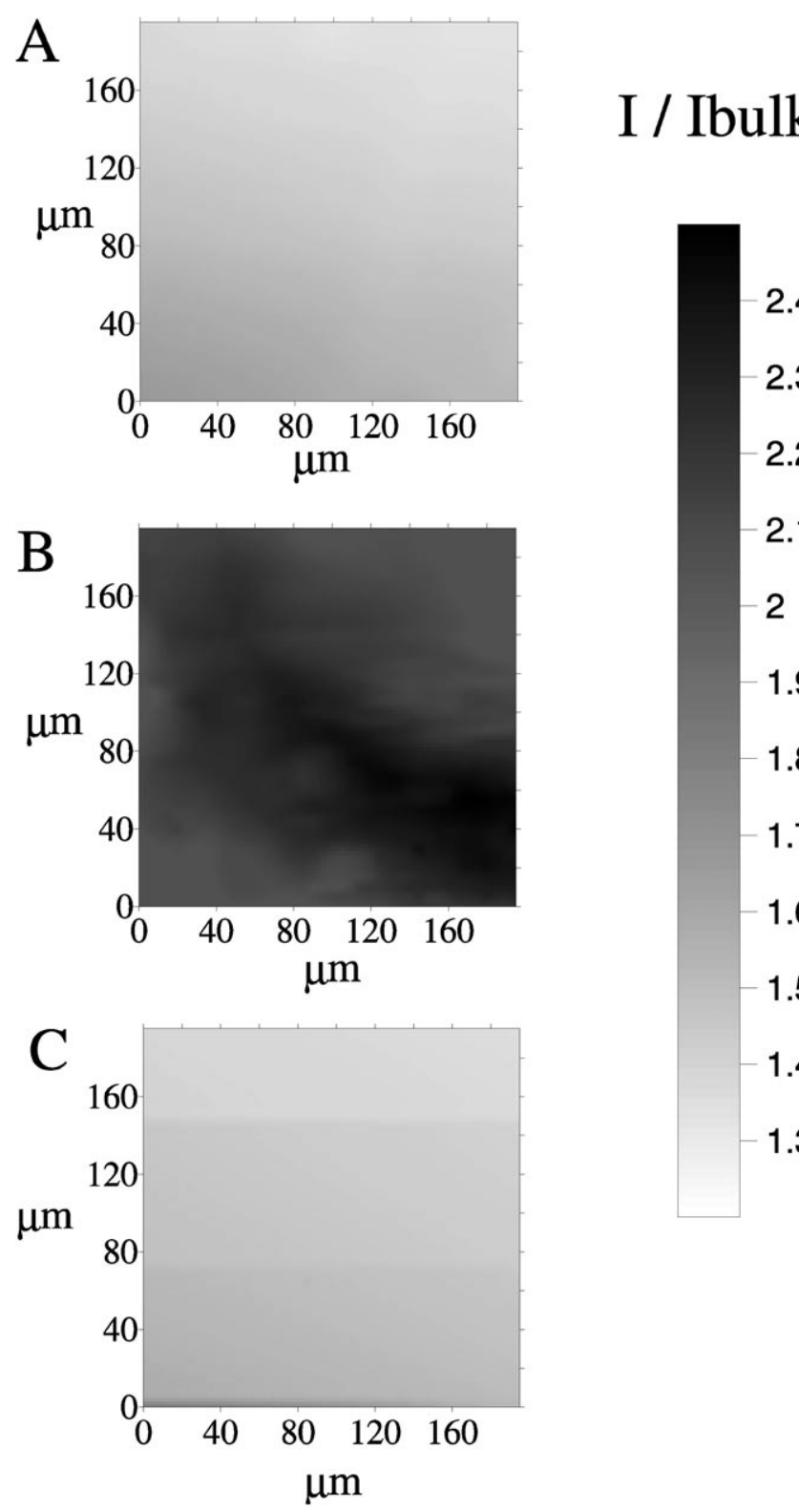

Fig. 5. SECM images obtained at different substrates with $20 \mathrm{mmolL}^{-1} \mathrm{MV}^{2+}$ as redox mediator. Bare gold electrode (A); gold electrode modified by an alloy of bismuth and lead (B), gold electrode after metal stripping $(\mathrm{C})$.

Table 2. Average normalized current and root mean square current fluctuation $\left(R_{q}\right)$ obtained within the area $200 \mu \mathrm{m} \times 200 \mu \mathrm{m}$ of the indicated substrates.

\begin{tabular}{llll}
\hline Substrate & $Z_{\text {aver }}$ & $R_{q}$ & $N$ \\
\hline Bare gold & 1.46 & 0.08 & 1600 \\
Gold coated with bismuth and lead & 2.17 & 0.13 & 1600 \\
\hline
\end{tabular}

\subsection{SEM Images}

In order to assess the validity of some of the previous hypotheses about uniformity of the deposits across the gold electrode surface, a series of measurements was per- formed using SEM. For sake of easier analysis, in this case, the metal films were deposited onto a gold fibre $100 \mu \mathrm{m}$ diameter. Figure 6 shows images obtained at the gold fibre coated with bismuth (Figure 6A), lead (Figure 6B) and a bismuth/lead alloy (Figure 6C). Plating conditions were the same as those used to obtain SECM images. SEM images indicate that i) several regions of uncoated gold are present after Bi plating; ii) bismuth and lead co-deposition provides deposits where regions of lead and bismuth can be clearly distinguished; lead deposit has a dendritic flower-like morphology; iii) the size of lead deposit is not uniform. All these characteristics agree well with SECM measurements. As for the dendritic, flower-like morphology of the $\mathrm{Pb}$ deposit, it can be due to the specific experimental conditions employed here. In fact, a similar lead morphology was reported recently from electroplating lead in $0.1 \mathrm{molL}^{-1} \mathrm{NaOH}$ solution at relatively negative applied potentials [52].

\subsection{ASV Behaviour}

1.7 In order to verify whether the inhomogeneity observed above at the $\mathrm{Bi} / \mathrm{Pb}$ coated gold electrode could affect its analytical performance for lead detection, a series of ASV measurements were carried out. In particular, ASV experiments were performed with a BiFE prepared in situ onto the gold disk substrate in a nitrogen-purged $0.1 \mathrm{molL}^{-1} \mathrm{NaOH}$ aqueous solution, containing $10 \mu \mathrm{molL}^{-1} \mathrm{Bi}(\mathrm{III})$ and $5 \mu \mathrm{molL}^{-1} \mathrm{~Pb}(\mathrm{II})$. Linear sweep voltammetry at $50 \mathrm{mV} \mathrm{s}^{-1}$ was employed during the stripping step. Deposition was performed at $-1.0 \mathrm{~V}$ while the solution was stirred. Typical ASV responses thus recorded are displayed in Figure 7a from which two peaks due to lead $(-0.71 \mathrm{~V})$ and bulk bismuth $(-0.42 \mathrm{~V})$ are evident; shoulders at -0.27 and $0.05 \mathrm{~V}$, attributable to bismuth forms bonded directly to gold, also appear $[11,18]$. However, no extra peaks attributable to possible species formed from interactions between lead and gold are evident (compare ASV responses obtained in the absence or in the presence of lead ions). This result is consistent with earlier findings reported in the literature [53-55], which were obtained by using square wave voltammetry as the stripping technique.

Since most of the SECM measurements were performed in aerated solutions, ASV measurements were also performed in an aqueous solution of composition as above, but not purged with nitrogen. Typical ASV responses obtained under the latter conditions are shown in Figure $7 \mathrm{~b}$. As is evident, in the absence of both bismuth and lead, a rather high background current due to oxygen reduction is recorded. After spiking the solution with bismuth and lead, ASV peaks due to the two metals are discernible upon their accumulation on the electrode surface. Calibration plots (not shown) performed under aerated conditions over the concentration range 0.5$5 \mu \mathrm{molL}^{-1}$ of $\mathrm{Pb}^{2+}$, while keeping the $\mathrm{Bi}^{3+}$ concentration constant at $10 \mu \mathrm{molL}^{-1}$, provided a linear response of peak current $(I)$ against bulk concentration $\left(C^{\mathrm{b}}\right)$, and the 

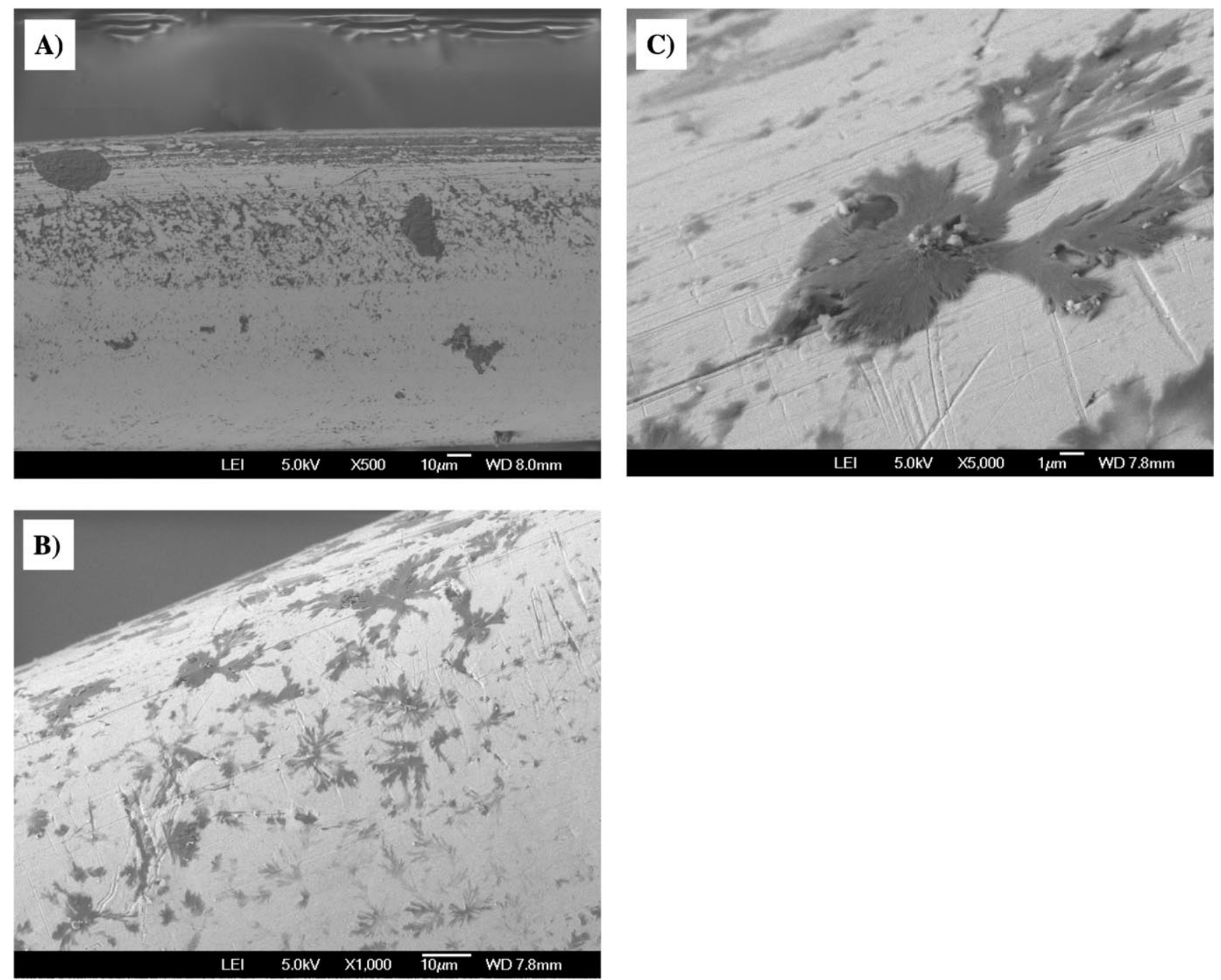

Fig. 6. SEM images obtained with different substrates. Gold wire modified with bismuth (A), lead (B) and bismuth and lead (C).

regression analysis of experimental points yielded: $I$ $(\mu \mathrm{A})=0.909+0.675 C^{\mathrm{b}}\left(\mu \mathrm{mol} \mathrm{L}{ }^{-1}\right)\left(R^{2}=0.997\right)$. Also reproducibility was satisfactory, it being within $5 \%$ r.s.d. (at $1 \mu \mathrm{mol} \mathrm{L}{ }^{-1} \mathrm{~Pb}^{2+}$ level, four replicates). It must be considered that a mathematical treatment of the ASVs, i.e., subtraction of the voltammograms in presence of oxygen from those in absence of oxygen provided very similar results (not shown). The latter procedure could eventually be employed for a faster, although less typical, metal ion detection.

These results overall confirm that gold is suitable as substrate for Bi film formation and for ASV measurements of lead in alkaline media, in spite of the apparent film heterogeneity observed from SECM and SEM measurements. Moreover, it is also evident that $\mathrm{Bi}^{3+}$ excess concentration values less than 10 still provides suitable ASV responses.

\section{Conclusions}

A SECM investigation on the activity and reactivity of bismuth and bismuth/lead films deposited onto a gold surface from alkaline medium is reported for the first time. SECM experiments carried out with methyl viologen as redox mediator indicate that both films are conductive and not uniformly plated. Corrosion of metal films has shown to occur in the aerated solution investigated, and the metal distribution across the surface was established by ASV-SECM measurements using a mercury microelectrode. Inhomogeneities in the plated films have been assessed from SECM images and confirmed by SEM images obtained under similar experimental conditions. The observed heterogeneity of the metals film upon plating simultaneously bismuth and lead, apparently, does not affect the analytical performance of the bismuth-coated gold electrode. 

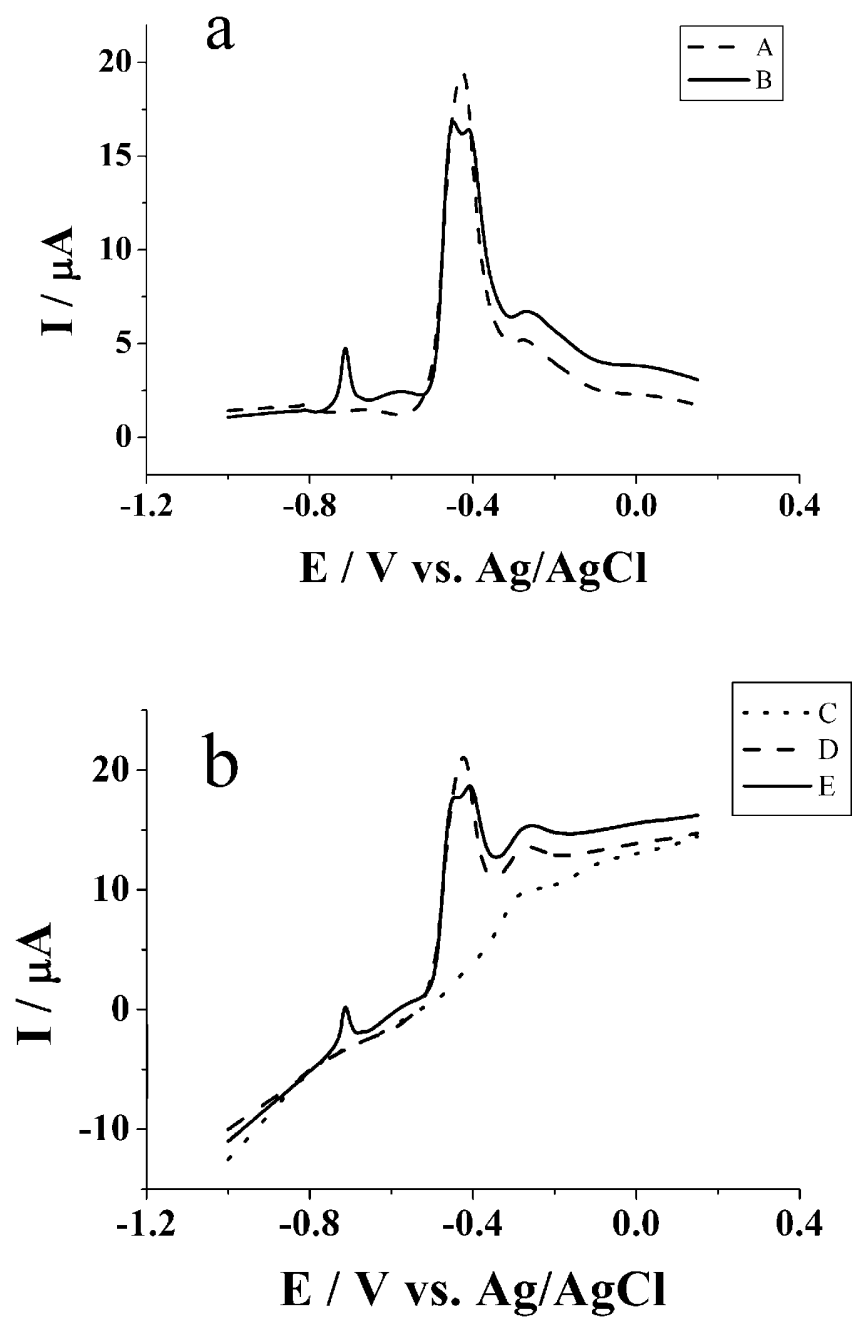

Fig. 7. Anodic stripping voltammograms recorded at a BiFE prepared onto a $2 \mathrm{~mm}$ diameter gold electrode in $0.1 \mathrm{molL}^{-1}$ $\mathrm{NaOH}$ solutions. (a) Solution purged with a nitrogen flux and spiked with $10 \mu \mathrm{molL}^{-1} \mathrm{Bi}^{3+}$ only (curve A) and $10 \mu \mathrm{molL}^{-1}$ $\mathrm{Bi}^{3+}+1 \mu \mathrm{molL} \mathrm{L}^{-1} \mathrm{~Pb}^{2+}$ (curve $\mathrm{B}$ ). (b) Aerated unspiked solution (curve C) and spiked with $10 \mu \mathrm{molL}^{-1} \mathrm{Bi}^{3+}$ only (curve D) and $10 \mu \mathrm{molL}^{-1} \mathrm{Bi}^{3+}+1 \mu \mathrm{molL}^{-1} \mathrm{~Pb}^{2+}$ (curve E). $E_{\mathrm{dep}}=-1.0 \mathrm{~V}$, $t_{\text {dep }}=500 \mathrm{~s}$, scan rate: $50 \mathrm{mV} \mathrm{s}^{-1}$.

\section{Acknowledgements}

The financial support from the Italian Ministry of the University and Research (MUR) and from CAPES and FAPESP (Brazil) is gratefully acknowledged.

\section{References}

[1] J. Wang, J. M. Lu, S. B. Hocevar, P. A. M. Farias, B. Ogorevc, Anal. Chem. 2000, 72, 3218.

[2] J. Wang, Electroanalysis 2005, 17, 1341.

[3] A. Economou, Trac - Trends Anal. Chem. 2005, 24, 334.

[4] I. Svancara, K. Vytras, Chem. Listy 2006, 100, 90.

[5] S. Daniele, M. A. Baldo, C. Bragato, Curr. Anal. Chem. 2008, 4, 215.

[6] B. J. Privett, J. H. Shin, M. H. Schoenfisch, Anal. Chem. 2008, 80, 4499.
[7] I. Svancara, C. Prior, S. B. Hocevar, J. Wang, Electroanalysis 2010, 22, 1405.

[8] S. B. Hocevar, B. Ogorevc, J. Wang, B. Pihlar, Electroanalysis 2002, 14, 1707.

[9] M. A. Baldo, S. Daniele, Anal. Lett. 2004, 37, 995.

[10] C. Kokkinos, A. Economou, Curr. Anal. Chem. 2008, 4, 183.

[11] L. Baldrianova, I. Svancara, A. Economou, S. Sotiropoulos, Anal. Chim. Acta 2006, 580, 24.

[12] I. Svancara, L. Baldrianova, E. Tesarova, S. B. Hocevar, S. A. A. Elsuccary, A. Economou, S. Sotiropoulos, B. Ogorevc, K. Vytras, Electroanalysis 2006, 18, 177.

[13] S. B. Hocevar, S. Daniele, C. Bragato, B. Ogorevc, Electrochim. Acta 2007, 53, 555.

[14] G. Grinciene, A. Selskiene, R. Verbickas, E. Norkus, R. Pauliukaite, Electroanalysis 2009, 21, 1743.

[15] A. Krolicka, A. Bobrowski, K. Kalcher, J. Mocak, I. Svancara, K. Vytras, Electroanalysis 2003, 15, 1859.

[16] S. Legeai, S. Bois, O. Vittori, J. Electroanal. Chem. 2006, $591,93$.

[17] L. M. S. Nunes, R. C. Faria, Electroanalysis 2008, 20, 2259.

[18] L. Baldrianova, I. Svancara, M. Vlcek, A. Economou, S. Sotiropoulos, Electrochim. Acta 2006, 52, 481.

[19] M. O. Salles, A. P. R. de Souza, J. Naozuka, P. V. de Oliveira, M. Bertotti, Electroanalysis 2009, 21, 1439.

[20] S. A. A. El Succary, I. Svancara, R. Metelka, L. Baldrianova, M. E. M. Hassouna, K. Vytras, Sci. Pap. Univ. Pardubice Ser. $A$ 2003, 9, 5 .

[21] A. Królicka, A. Bobrowski, Electrochem. Communn. 2004, 6, 99.

[22] A. J. Bard, M. V. Mirkin, Scanning Electrochemical Microscopy Marcel Dekker, New York 2001.

[23] A. J. Bard, F. R. F. Fan, J. Kwak, O. Lev, Anal. Chem. 1989, 61, 132.

[24] C. Wei, A. J. Bard, J. Electrochem. Soc. 1995, 142, 2523.

[25] M. A. Alpuche-Aviles, J. E. Baur, D. O. Wipf, Anal. Chem. 2008, 80,3612 .

[26] M. V. Mirkin, B. R. Horrocks, Anal. Chim. Acta 2000, 406, 119.

[27] L. Guadagnini, A. Maljusch, X. X. Chen, S. Neugebauer, D. Tonelli, W. Schuhmann, Electrochim. Acta 2009, 54, 3753.

[28] D. Battistel, S. Daniele, R. Gerbasi, M. A. Baldo, Thin Solid Films 2010, 518, 3625.

[29] A. J. Bard, G. Denuault, C. Lee, D. Mandler, D. O. Wipf, Accounts Chem. Res. 1990, 23, 357.

[30] J. L. Amphlett, G. Denuault, J. Phys. Chem. B 1998, 102, 9946.

[31] P. Sun, F. O. Laforge, M. V. Mirkin, Phys. Chem. Chem. Phys. 2007, 9, 802.

[32] J. Kwak, J. Bard, Anal. Chem. 1989, 61, 1221.

[33] C. Lefrou, R. Cornut, ChemPhysChem, 2010, 11, 547.

[34] R. Cornut, M. Mayoral, D. Fabre, J. Mazueroll, J. Electrochem. Soc. 2010, 157, F77-F82.

[35] S. Daniele, C. Bragato, I. Ciani, M. A. Baldo, Electroanalysis 2003, 15, 621.

[36] G. Lindsey, S. Abercrombie, G. Denuault, S. Daniele, E. De Faveri, Anal. Chem. 2007, 79, 2952.

[37] A. Bobrowski, K. Kalcher, K. Kurowska, Electrochim. Acta 2009, 54, 7214.

[38] M. A. Baldo, S. Daniele, M. Corbetta, G. A. Mazzocchin, Electroanalysis 1995, 7, 980.

[39] M. Corbetta, M. A. Baldo, S. Daniele, G. A. Mazzocchin, Ann. Chim. (Rome) 1996, 86, 77.

[40] S. Daniele, C. Bragato, M. A. Baldo, G. A. Mazzocchin, Ann. Chim. (Rome), 2002, 92, 203.

[41] C. Bragato, S. Daniele, M. A. Baldo, G. Denuault, Ann. Chim. (Rome), 2002, 92, 153. 
[42] E. E. Stansbury, R. A. Buchanan, Fundamentals of Eletrochemical Corrosion, ASM International, USA 2000.

[43] D. Jagner, Anal. Chem. 1979, 51, 342.

[44] I. Ciani, S. Daniele, C. Bragato, M. A. Baldo, Electrochem. Commun. 2003, 5, 354.

[45] D. Rudolph, S. Neuhuber, C. Kranz, M. Taillefert, B. Mizaikoff, Analyst 2004, 129, 443.

[46] M. Janotta, D. Rudolph, A. Kueng, C. Kranz, H.-S. Voraberger, W. Waldhauser, B. Mizaikoff, Langmuir 2004, 20, 8634.

[47] J. Mauzeroll, E. A. Hueske, A. J. Bard, Anal. Chem. 2003, 75,3880 .

[48] S. Daniele, I. Ciani, M. A. Baldo, C. Bragato, Electroanalysis 2007, 19, 2067.
[49] D. Ruhlig, W. Schuhmann, Electroanalysis 2007, 19, 191.

[50] J. Mauzerroll, M. Buda, A. J. Bard, F. Prieto, M. Rueda, Langmuir 2002, 18, 9453.

[51] J. L. P. Siqueira, I. A. Carlos, J. Power Sources 2007, 166, 519.

[52] E. M. Richter, J. J. Pedrotti, L. Angnes, Electroanalysis 2003, 15, 1871 .

[53] S. Laschi, I. Palchetti, M. Mascini, Sens. Actuators B, Chem. 2006, 114, 460.

[54] C. Garnier, L. Lesven, G. Billon, A. Magnier, O. Mikkelsen, I. Pizeta, Anal. Bioanal. Chem. 2006, 386, 313.

[55] Handbook of Chemistry and Physics, CRC Press, Boca Raton 1991-1992. 